\title{
Native Oils from Apple, Blackcurrant, Raspberry, and Strawberry Seeds as a Source of Polyenoic Fatty Acids, Tocochromanols, and Phytosterols: A Health Implication
}

\author{
Marek Pieszka, ${ }^{1}$ Władysław Migdal, ${ }^{2}$ Robert Gąsior, ${ }^{3}$ Magdalena Rudzińska, \\ Dorota Bederska-Lojewska, ${ }^{1}$ Magdalena Pieszka, ${ }^{5}$ and Paulina Szczurek ${ }^{1}$ \\ ${ }^{1}$ Department of Animal Nutrition and Feed Science, National Research Institute of Animal Production, 32-083 Balice, Poland
${ }_{2}^{2}$ Department of Animal Products Technology, University of Agriculture in Krakow, Balicka 122, 31-149 Kraków, Poland
${ }^{3}$ Central Laboratory, National Research Institute of Animal Production, 32-083 Balice, Poland
${ }^{4}$ Institute of Plant Products Technology, University of Life Sciences in Poznan, Wojska Polskiego 31, 60-624 Poznan, Poland
${ }^{5}$ Department of Horse Breeding, Institute of Animal Science, Agricultural University, Mickiewicza Street 24/28, 30-059 Kraków, Poland
}

Correspondence should be addressed to Marek Pieszka; marek.pieszka@izoo.krakow.pl

Received 14 October 2014; Accepted 2 December 2014

Academic Editor: Iciar Astiasaran

Copyright (C) 2015 Marek Pieszka et al. This is an open access article distributed under the Creative Commons Attribution License, which permits unrestricted use, distribution, and reproduction in any medium, provided the original work is properly cited.

\begin{abstract}
The oils from strawberry, blackcurrant, raspberry, and apple seeds were characterized by a high content of unsaturated fatty acids $(90.8 \%, 88.6 \%, 94.0 \%$, and $86.9 \%$, resp.). Strawberry and raspberry oils had high levels of C18:2 (45.4\% and $49.0 \%)$ and $\alpha \mathrm{C} 18: 3$ (29.0\% and 33.0\%, resp.). Blackcurrant oil was the richest source of $\gamma \mathrm{C18:3}$ (18.5\%) and C18:4 (3.6\%). Apple oil had high levels of C18:2 (55.5\%) and C18:1 (29.4\%). Blackcurrant oil had $229.5 \mathrm{mg} / 100 \mathrm{~g}$ of tocochromanols, predominantly $\gamma$-tocopherol $(117.8 \mathrm{mg} / 100 \mathrm{~g})$ and $\alpha$-tocopherol $(84.3 \mathrm{mg} / 100 \mathrm{~g})$. Raspberry oil was rich in $\gamma$-, $\alpha$-, and $\delta$-tocopherol (193.5; 65.6; and $32.2 \mathrm{mg} / 100 \mathrm{~g}$, resp.). Strawberry oil contained $\gamma$ - and $\delta$-tocopherol, 49.0 and $6.1 \mathrm{mg} / 100 \mathrm{~g}$, respectively. Apple contained all isomers of $\alpha$-, $\beta$-, $\gamma$-, and $\delta$-tocopherols at 41.7, 62.7, 13.6, and $21.8 \mathrm{mg} / 100 \mathrm{~g}$, respectively. The level of tocotrienols in the analysed oils ranged from 0.85 to $6.73 \mathrm{mg} / 100 \mathrm{~g}$. Ten different phytosterols were found in the tested oils. The richest sources of phytosterols were blackcurrant oil $(6824.9 \mu \mathrm{g} / \mathrm{g})$ followed by raspberry $(5384.1 \mu \mathrm{g} / \mathrm{g})$, strawberry $(4643.1 \mu \mathrm{g} / \mathrm{g})$, and apple oil $(3460.0 \mu \mathrm{g} / \mathrm{g})$. The dominant compound in the analysed oils was sitosterol, from $2630 \mu \mathrm{g} / \mathrm{g}$ in apple oil to $3630 \mu \mathrm{g} / \mathrm{g}$ in blackcurrant oil.
\end{abstract}

\section{Introduction}

Poland is the leading European manufacturer of fruit juice, in particular concentrated apple juice. Fruit juice and drink production was 1100 thousand tons in the 2005/2006 season and varied between 900 and 1300 thousand tons in the subsequent years, whereas the amount of berries produced for juice is almost 500 thousand tons $[1,2]$. A valuable coproduct of juice production is pressing residue known as pomace, which in addition to being high in nutrients is a rich source of biologically active substances called nutraceutics, that is, unsaturated fatty acids, natural antioxidants (phenolic acids, flavonoids, anthocyans, tocopherols, and tocotrienols), carotene pigments, phytosterols, minerals, aromatic substances, pigments, bacterial and viral inhibitory substances, ballast compounds, fibre, and pectins [2-7]. Dried pomace is put through a sifting process to produce seeds that form $5-70 \%$ of total pomace weight depending on type of dried fruit. Increasing attention has been paid during the last decade to the fact that some seeds may contain fats of high nutritional, dietetic, and even therapeutic value. The major lipid components of oils are triacylglycerols (esters of glycerol and fatty acids). Less important components found in much smaller amounts are nontriacylglycerol compounds such as phospholipids, sterols, tocopherols, and carotenoids $[8,9]$. These components not only determine the nutritional value of the oils but also have a significant effect on their stability, in particular the oxidative stability.

Seeds of berries, including strawberries, raspberries, blackcurrant, and apples, are a rich source of polyenoic 
fatty acids (EUFA). These acids are not synthesized in the human body and have to be supplied through diet. Human nutritionists recommend that Poles should consume diets lower in fats with the change of its structure by increasing the intake of fats that contain polyenoic fatty acids. In addition to linoleic acid (LA) and long-chain polyenoic fatty acids (LC PUFA), an important role among them is played by 18 carbon polyenoic fatty acids having a triene structure $-\alpha$ linolenic (ALA) and $\gamma$-linolenic (GLA) - which belong to two biochemically different families of $n-3$ and $n-6$. It has recently been emphasized that $n-3$ fatty acids serve important physiological and health-promoting roles, especially in preventing cardiovascular diseases [10]. Considerable attention has also been given to the health-promoting role of $\gamma$-linolenic acid, especially with regard to inflammatory, allergic, and cardiovascular diseases [11].

In addition to these fatty acids, the oils from strawberry, raspberry, blackcurrant, and apple seeds contain a number of antioxidant, anti-inflammatory, antiatherosclerotic, and anticancerous substances, including tocochromanols, carotenoids, flavonoids, phytosterols, and phenolic acids $[5,8$, 12-14]. Plant fatty acids, which belong to a group of essential unsaturated fatty acids (EUFA), are characterized by high biological activity.

Recent years have seen much more intensive research on compounds that protect the body from the harmful effects of free radicals and other active forms of oxygen. Lipophilic components of vegetable oils, which show antioxidant activity and an ability to scavenge free radicals, are worthy of special notice. To date, vegetable oils rich in 18 -carbon polyenoic fatty acids having a triene structure were used as pharmaceutical preparations available in capsules. However, the current oil production technology that uses cold-pressing in nitrogen gas or supercritical carbon dioxide extraction enables the oils to be obtained in almost unchanged form. They are more abundant in side compounds of high biological and antioxidant activity. Occurrence of antioxidants that inhibit unfavourable changes and knowledge of their activity and stability is essential not only to technologists but also to nutritionists. The shelf life of oils can be extended by using a variety of procedures that protect freshly extracted oils, such as limiting or eliminating oxygen contact, light exposure, and contact with prooxidative metal (copper and iron) ions, as well as supplementing the oil with oxidation inhibiting substances. Various antioxidants are used for this purpose. Efforts are made to limit the use of synthetic antioxidants on the grounds of health risks. Considerable emphasis is placed on the use of natural or nature-identical antioxidants. Their broad antioxidative properties may help to limit autoxidation of vegetable oils rich in polyenoic fatty acids having a triene structure. When they are added to the diet, they may have beneficial effects on the human body because of their free radical scavenging capacity.

In a search for new sources of these biologically valuable fats, we performed chemical analyses of oils obtained from the pressing of strawberry, raspberry, blackcurrant, and apple seeds in terms of the composition and content of fatty acids, tocopherols, tocotrienols, and phytosterols.

\section{Materials and Methods}

2.1. Materials and Extraction of Fat from the Seeds. Oils from blackcurrant, raspberry, strawberry, and apple seeds originated from Mega-Sort company (Poland), which specializes in the drying and packaging of fruit pomace produced after extraction of fruit and vegetable juices. Pomace with about 55\% moisture content, originating from Hortex company (Poland), was dried on drum driers to reduce the moisture below $10 \%$. Dried fruit pomace was then cut and ground and the seeds were separated. The production line (Scorpion, Poland) included a chopper, a separator, and a pneumatic tunnel, in which the seeds were separated from the other parts. Oils were obtained from the seeds on a standard technological line used for cold-pressing of oilseeds (Farmet, Czech Republic) and equipped with a UNO screw press, a sedimentation tank, and board and candle filters. Seeds were subjected to a press head temperature of $55^{\circ} \mathrm{C}$ for $20 \mathrm{~s}$. The pressed and filtered oils from raspberry and strawberry seeds were placed in dark glass containers with added $\mathrm{N}_{2}$, tightly closed, and refrigerated at $4^{\circ} \mathrm{C}$ until further analyses.

\subsection{Analytical Methods}

2.2.1. Determination of Fatty Acid Composition in Oils. Gas chromatography was used to determine higher fatty acids in fruit seed oils in the form of methyl esters, following saponification of the fatty acids contained in the sample.

Reagents. Gradient grade $n$-hexane for HPLC analysis, $\mathrm{BF}_{3} /$ methanol (Merck, Germany) and (pure for analysis) $\mathrm{NaOH}$, chloroform, methanol, and $\mathrm{NaCl}$ (Chempur, Poland) were used. Sodium chloride $(0.58 \%)$ and potassium hydroxide solutions $(0.5 \mathrm{~N})$ were made using double-distilled water.

Equipment. A Varian 3400 gas chromatograph (USA) equipped with an $8200 \mathrm{CX}$ autosampler and FID detector was used. Data were integrated using Varian Star 4.5 software. Conversion was carried out using Excel. Sample preparation also involved the use of $7 \mathrm{~mL}$ screw-cap tubes (Schott), chromatography vials, a water bath, and a nitrogen solvent evaporation system.

Conditions of Chromatographic Analysis. Chromatographic separation was performed on CP Wax 58 column $(0.53 \mathrm{~mm} \times$ $1 \mu \mathrm{m}$ ) (Chrompack, USA) using temperature programmes of $60-188^{\circ} \mathrm{C}\left(4^{\circ} \mathrm{C} / \mathrm{min}\right)$ followed by $60-220^{\circ} \mathrm{C}\left(5^{\circ} \mathrm{C} / \mathrm{min}\right)$. Injector and FID detector temperature were 200 and $260^{\circ} \mathrm{C}$, respectively. Helium was used as a carrier gas $(6 \mathrm{~mL} / \mathrm{min})$. Hexane sample solutions $(1 \mu \mathrm{L})$ were injected onto the column.

Procedure for PUFA Determination. Oil samples (about $100 \mathrm{mg}$ ) were weighed into $7 \mathrm{~mL}$ screw-cap tubes (Schott), saponified with $0.5 \mathrm{~N} \mathrm{NaOH}$ in methanol $\left(80^{\circ} \mathrm{C}\right)$, and esterified with $\mathrm{BF}_{3}$ in methanol $[15,16]$. Methyl esters of fatty acids were extracted with hexane. After salting out with saturated $\mathrm{NaCl}$ solution $(0.58 \%)$, the hexane layer was collected into a chromatography vial and determined by gas chromatography. 
The analyses were performed using standard solutions containing a mixture of standards $(0.02-3.3 \mathrm{mg} / \mathrm{mL}$ in hexane) of the following fatty acids: caprylic (C8), capric (C10), lauric (C12), myristic (C14), palmitic (C16), palmitoleic (C16:1), stearic (C18), oleic (C18:1), linoleic (C18:2), linolenic (C18:3), $\gamma$-linolenic (gC18:3), stearidonic (C18:4), arachidic (C20), arachidonic (C20:4), behenic (C22), erucic (C22:1), eicosapentaenoic (EPA, C20:5), docosahexaenoic (DHA, C22:6), eicosenoic (C20:1), eicosadienoic (C20:2), and eicosatrienoic $(\mathrm{C} 20: 3, \omega 6)$ acids, all purchased from Sigma-Aldrich (USA), and conjugated linoleic acid isomers (CLA: c9-t11, t10-c12, and c9-c11) purchased from Larodan $A B$ (Sweden). Final results were adjusted for fatty acid content in a blank sample, which was prepared in a similar manner to the sample but without weighed sample.

2.3. Determination of $\alpha-, \beta-, \gamma$-, and $\delta$-Tocopherols and Tocotrienols in Oils. Tocopherols $(\alpha-, \beta-, \gamma$-, and $\delta$-tocopherols) and tocotrienols $(\alpha-, \beta-, \gamma$-, and $\delta$-tocotrienols) in fruit seed oils were determined according to the method described by Gąsior et al. [17] using normal-phase high-performance liquid chromatography (NP-HPLC) [18]. Tocopherols and tocotrienols were determined after saponification of the sample in the presence of potassium hydroxide and ethanol, followed by extraction with a mixture of ethyl acetate/hexane $(1 / 9, \mathrm{v} / \mathrm{v})$. Analyses were performed with standard solutions $(0-24 \mu \mathrm{g} / \mathrm{mL})$ containing a mixture of tocol standards, using $\alpha$-tocopherol from Fluka (USA), $\beta$-, $\gamma$-, and $\delta$-tocopherols from Calbiochem (USA), and tocotrienols from Davos Life Science Pte Ltd. (Singapore). Final results were corrected for tocol content in a blank sample and recovery determined by the standard addition method (89-102\%).

2.3.1. Reagents. Gradient grade $n$-hexane for HPLC analysis (Merck, Germany) and (pure for analysis) ethyl acetate, acetic acid, isopropyl alcohol (2-propanol), and ethanol 9596\% (Chempur, Poland) were used in addition to potassium hydroxide, sodium chloride (POCH, Poland), and pyrogallol ( $>98 \%$, Fluka, USA). Sodium chloride $(10 \mathrm{~g} / \mathrm{L})$ and potassium hydroxide solutions $(600 \mathrm{~g} / \mathrm{L})$ were made using doubledistilled water.

2.3.2. Equipment and Standardization of Standards. An Agilent Series 1100 HPLC system (USA) equipped with a pump, autosampler, and fluorescence detector was used. Data were integrated using Agilent ChemStation software. Calculations were carried out using Excel. Sample preparation also involved the use of $12 \mathrm{~mL}$ screw-cap tubes (Schott), screw-cap bottles $(15 \mathrm{~mL})$, a shaker (Vortex, Germany), an ultrasound bath, and a water bath. Standards (alcohol solutions) were standardized [17] using a Beckman DU 640 spectrophotometer based on tabular data for reference extinction values $\left(\mathrm{E}_{1} \mathrm{~cm} \mathrm{1 \% )}\right.$ of 75.8, 89.4, 91.4, 87.3, 86.0, 86.2, 91.0, and 85.8 for $\alpha$-tocopherol, $\beta$-tocopherol, $\gamma$-tocopherol, $\delta$-tocopherol, $\alpha$ tocotrienol, $\beta$-tocotrienol, $\gamma$-tocotrienol, and $\delta$-tocotrienol, respectively [19].

2.3.3. Conditions of HPLC Chromatographic Analysis. Chromatographic separation was performed on a LiChroCART
250-4 Lichrospher Si 60 column $(5 \mu \mathrm{m}$, Merck, Germany) under the following conditions: FL detector, $\lambda$ wavelength: Ex290 nm Em330 nm; injection $50 \mu \mathrm{L}$; eluent (flow rate $1.6 \mathrm{~mL} / \mathrm{min}$ ), $n$-hexane : ethyl acetate: acetic acid $(97.3: 1.8: 0.9 \mathrm{v} / \mathrm{v} / \mathrm{v})$, duration of analysis $37 \mathrm{~min}$, pressure 58-68 bar. Prior to analysis, the eluent was degassed in an ultrasound bath. Between analyses of each sample, the column was conditioned for $70 \mathrm{~min}$ using $10 \%$ isopropanol solution in $n$-hexane $(\mathrm{v} / \mathrm{v})$.

2.3.4. Determination Procedure. Oil samples (about $20 \mathrm{mg}$ ) were weighed into $12 \mathrm{~mL}$ Schott tubes with an accuracy of $0.0001 \mathrm{~g} .1 \mathrm{~mL}$ of pyrogallol in ethanol $(60 \mathrm{~g} / \mathrm{L}), 0.5 \mathrm{~mL}$ of aqueous solution of potassium hydroxide $(600 \mathrm{~g} / \mathrm{L}), 0.5 \mathrm{~mL}$ of aqueous solution of sodium chloride $(10 \mathrm{~g} / \mathrm{L})$, and $0.5 \mathrm{~mL}$ of ethanol were added to these. Vials were screw-capped, agitated on a Vortex shaker for about $10 \mathrm{~s}$, and then transferred to a water bath $\left(70^{\circ} \mathrm{C}\right)$, where the samples were saponified for $45 \mathrm{~min}$. After cooling, $4 \mathrm{~mL}$ of aqueous solution of sodium chloride $(10 \mathrm{~g} / \mathrm{L})$ was added and this was extracted twice $(4 \mathrm{~mL}$ each) with a mixture of ethyl acetate and $n$-hexane $(1: 9, \mathrm{v} / \mathrm{v})$, shaking (Vortex) the screw-capped tube for about $0.1 \mathrm{~min}$. The extracts were pooled and evaporated dry under nitrogen $\left(15 \mathrm{~mL}\right.$ bottles) in a water bath $\left(40^{\circ} \mathrm{C}\right)$. After dissolving the residue in $0.5 \mathrm{~mL}$ of a $1 \%$ mixture of isopropanol and $n$-hexane $(\mathrm{v} / \mathrm{v})$, the solutions $(50 \mu \mathrm{L})$ were injected onto a chromatographic column. The same procedure was carried out when making blank samples except that no sample was added.

2.4. Determination of Phytosterols in Oils. The sterol content of lipids from the fruits was analysed according to the AOCS Official Method Ch 6-91 [20]. Phytosterol standards originated from Calbiochem (USA). $0.05 \mathrm{~g}$ of oils was weighed with an accuracy of $0.001 \mathrm{~g}$ into the reaction tubes, adding $100 \mu \mathrm{L}$ of $5 \alpha$-cholestan as an internal standard and the samples were saponified in $2 \mathrm{~mL}$ of $1 \mathrm{M} \mathrm{KOH}$ in methanol for $18 \mathrm{~h}$. After adding $2 \mathrm{~mL}$ of water, sterols were extracted three times with a mixture of hexane and MTBE $(1: 1)$ for 5,3 , and 2 min. Then the solvent was evaporated under a stream of nitrogen and the samples were dissolved in anhydrous pyridine and silylated with Sylon BTZ reagent (Sigma-Aldrich, USA). Sterols were separated using capillary column DB-35 ms $(25 \mathrm{~m} \times 0.2 \mathrm{~mm} \times 0.33 \mu \mathrm{m}$; J \& W Scientific, Folson, CA, USA) on a HP 5890 Series II gas chromatograph. Hydrogen was used as a carrier gas at a flow rate of $1.5 \mathrm{~mL} \mathrm{~min}^{-1}$. The following temperature programme was used for the column from $100^{\circ} \mathrm{C}$ to $250^{\circ} \mathrm{C}\left(25^{\circ} \mathrm{C} / \mathrm{min}\right)$ for $1 \mathrm{~min}$ then to $290^{\circ} \mathrm{C}$ $\left(3^{\circ} \mathrm{C} / \mathrm{min}\right)$. The initial and final temperature were held for 5 and $15 \mathrm{~min}$, respectively. Injector and detector temperature were $300^{\circ} \mathrm{C}$. Sample injection was performed by injecting $1 \mu \mathrm{L}$ of the sample onto the column, using the splitless mode of injection for $1 \mathrm{~min}$. Sterols were identified by comparing the retention times of these authentic standards.

2.5. Determination of Acid Value in Oils. About $5 \mathrm{~g}$ of oil was weighed into a $250 \mathrm{~mL}$ flask with an accuracy of $0.01 \mathrm{~g}$. The sample was dissolved in $50 \mathrm{~mL}$ of hot ethanol. Titration was performed by mixing the flask content with $\mathrm{KOH}$ solution in 
ethanol to the end point in the presence of phenolphthalein. The end point was when adding one drop of lye which caused a weak but perceivable change in colour for at least $15 \mathrm{~s}$. The blank sample was titrated [21].

The acid value was calculated using the following formula:

$$
\mathrm{LK}=56.1 *(V-V 0) * \frac{c}{m},
$$

where $m$ : weight of fat, $V$ : volume of potassium hydroxide solution used for fat sample titration, $V 0$ : volume of potassium hydroxide solution used for blank sample titration, and $c$ : concentration of $\mathrm{KOH}$ solution $(0.1 \mathrm{~N})$.

2.6. Determination of Peroxide Value in Oils. About $2 \mathrm{~g}$ of oil was weighed with an accuracy of $0.001 \mathrm{~g}$ and transferred into a conical flask. The flask was filled with $10 \mathrm{~cm}^{3}$ of chloroform, mixed until the fat was completely dissolved, filled with $15 \mathrm{~cm}^{3}$ of acetic acid and $1 \mathrm{~cm}^{3}$ of KI solution, and closed with a ground-in stopper. Flask content was agitated for $1 \mathrm{~min}$ and then left in the dark for $5 \mathrm{~min} .75 \mathrm{~cm}^{3}$ of distilled water (rinsing the stopper thoroughly) and 5 drops of starch solution were added to this, which after mixing was titrated with a $0.002 \mathrm{~N}$ solution of sodium thiosulfate. The blank sample was prepared simultaneously [22].

Peroxide value was calculated using the following formula:

$$
\mathrm{LOO}=0.002 *(a-b) * \frac{1000}{m}
$$

[milliequivalents of active $\mathrm{O}_{2} / \mathrm{kg}$ ],

where $a$ : volume of sodium thiosulfate solution used for fat sample titration $\left(\mathrm{cm}^{3}\right), b$ : volume of sodium thiosulfate solution used for blank sample titration $\left(\mathrm{cm}^{3}\right)$, and $m$ : weight of sample $(\mathrm{g})$.

2.7. Statistical Analysis. Analysis of the chemical composition, the content of bioactive compounds, and physicochemical properties in the oils was performed in 3 replications; the results were expressed as mean and coefficients of variation (CV) (Table 1).

\section{Results and Discussion}

Biooils are biologically the most valuable plant fats due to their composition that reflects the actual structure of all substances found in the seeds from which the oil was extracted. The WHO/FAO Codex Alimentarius Commission provided a definition of biooil that corresponds to virgin oil and determines the conditions for its extraction. Only mechanical extraction methods that ensure high quality of biooils are allowed. Pressing of oilseeds using hydraulic or screw press at low temperature regimes is therefore the only expression method. The procedures allowed to remove impurities from oil include water washing and centrifugation as well as sedimentation and filtration. No phospholipids, tocopherols, sterols, or carotenoids are removed from these oils. The high quality of these oils is conditional on the use of selected, fully mature seeds. The moisture content of the seeds obtained was in the range of 7.5-9.5\%. Most oil was found in apple seeds, followed by strawberry, blackcurrant, and raspberry seeds $(20.2,18.5,16.2$, and $13.5 \%$, resp.). These results are confirmed by the findings of other authors $[14,23,24]$ and the small differences are due to the quality of extracted seeds and oil extraction technique (including press type and filtration method). The analysed oils were characterized by increased peroxide values (within the normal range) of 8.78, 8.39, 9.45, and $10.59 \mathrm{mq} \mathrm{O}_{2} / \mathrm{kg}$ for strawberry, blackcurrant, raspberry, and apple seed oils, respectively. Cold-pressed virgin oils are characterized by increased peroxide and acid values as a result of protein, mineral, and other impurities that favour oxidation processes being left after oil extraction $[5,25]$.

3.1. Fatty Acids in Oils from Strawberry, Blackcurrant, Raspberry, and Apple Seeds. In addition to lifestyle and living conditions, diet is one of the most important determinants of our health and well-being. Advances in understanding the action of diet ingredients that may have a beneficial effect on the human body made it possible to design and produce food with specific health-promoting effects, rich in various bioactive components. Among these, polyenoic fatty acids are important, which play a significant role in preventing metabolic diseases of modern civilization. Polish fat products (oils, margarines, spreads, $100 \%$ fats) contain small amounts of $n$-3 polyenoic fatty acids but practically have no $\gamma$-linolenic acid. For this reason, efforts are made to increase their dietary content. Some vegetable oils are a rich source of these acids.

Oils considered a rich source of PUFA having a triene structure $(\alpha$-linoleic acid C18:3 $\Delta$ 9,12,15 and $\gamma$-linolenic acid C18:3 $\Delta 6,9,12)$ - such as linseed, false flax, hemp, borage, and vipers bugloss, as well as strawberry, blackcurrant, raspberry, and apple seed oils-are characterized by widely different composition and content of individual fatty acids. This particularly refers to the group of polyenoic acids, including those having a triene structure. The composition of fatty acids in the oils from strawberry, blackcurrant, raspberry, and apple seeds was characterized by a high content of unsaturated fatty acids $(90.8 \%, 88.6 \%, 94.0 \%$, and $86.9 \%$, resp.) (Table 2$)$. The largest differences in the fatty acid profile of the analysed oils were observed within $\alpha$-linolenic and linoleic acids. Oils from strawberry and raspberry seeds had high levels of linoleic acid C18:2 (45.4\% and 49.0\%) and alpha-linolenic acid $\alpha \mathrm{C} 18: 3$ (29.0\% and 33.0\%, resp.). The richest source of gamma-linoleic $(\gamma \mathrm{C} 18: 3)$ and stearidonic acids (C18:4) was blackcurrant seed oil (18.5\% and 3.6\%, resp.). Apple seed oil had a high content of oleic acid C18:1 (29.4\%), which is in agreement with the findings of Yukui et al. [24]. Linseed oil is one of the richest sources of $\alpha$-linolenic acid, whose average content in commercial oil is $57.3 \%$, as confirmed by Choo et al. [26].

The analysed oils were found to be high in $\alpha$-linolenic acid; this especially concerned oils from strawberry, raspberry, and blackcurrant seeds $(29.0 \%, 33.0 \%$, and $13.5 \%$, resp.). In the apple seed oil, the level of $\alpha$-linolenic acid did not exceed $1 \%$. In addition, considerable amounts of this acid are found in linseed, false flax, vipers bugloss, and hemp oils $[14,26-29]$. 
TABLE 1: Physicochemical properties of oils from strawberry, raspberry, blackcurrant, and apple seeds.

\begin{tabular}{|c|c|c|c|c|}
\hline Characteristics & Strawberry seed oil & Raspberry seed oil & Blackcurrant seed oil & Apple seed oil \\
\hline Content of oil (\% dry matter) & $18.56 \pm 0.32$ & $13.52 \pm 0.31$ & $16.20 \pm 0.29$ & $20.22 \pm 0.32$ \\
\hline Moisture content of seeds (\%) & $7.78 \pm 0.11$ & $6.96 \pm 0.10$ & $8.01 \pm 0.12$ & $8.84 \pm 0.13$ \\
\hline Acid value (mg KOH/g) & $2.09 \pm 0.004$ & $1.74 \pm 0.002$ & $4.10 \pm 0.006$ & $1.36 \pm 0.002$ \\
\hline Peroxide value $\left(\mathrm{mq} \mathrm{O}_{2} / \mathrm{kg}\right)$ & $8.78 \pm 0.02$ & $8.39 \pm 0.01$ & $9.45 \pm 0.03$ & $10.59 \pm 0.04$ \\
\hline
\end{tabular}

Values are mean \pm and coefficients of variation $(\mathrm{CV})$.

TABLE 2: Composition of fatty acids in oils from strawberry, raspberry, blackcurrant, and apple seeds (\% of total fatty acids).

\begin{tabular}{|c|c|c|c|c|}
\hline Fatty acids & Strawberry seed oil & Raspberry seed oil & Blackcurrant seed oil & Apple seed oil \\
\hline $\mathrm{C} 10$ & 0.01 & 0.00 & 0.01 & 0.00 \\
\hline C 16 & 6.20 & 4.19 & 9.63 & 9.50 \\
\hline C $16: 1(n-7)$ & 0.25 & 0.14 & 0.17 & 0.00 \\
\hline C 18 & 1.89 & 1.19 & 1.39 & 1.82 \\
\hline C $18: 1(n-9)$ & 15.51 & 11.70 & 12.09 & 29.36 \\
\hline C $18: 2(n-6)$ & 45.45 & 49.01 & 38.64 & 55.54 \\
\hline$\gamma 18: 3(n-6)$ & 0.04 & 0.04 & 18.54 & 0.34 \\
\hline C $18: 3(n-3)$ & 29.05 & 33.02 & 13.57 & 0.85 \\
\hline C 18:4 (n-3) & 0.00 & 0.00 & 3.58 & 0.00 \\
\hline C 18:2 (CLA) c9-c11 & 0.00 & 0.00 & 0.11 & 0.00 \\
\hline C 20 & 0.91 & 0.45 & 0.21 & 1.56 \\
\hline C 20:1 & 0.27 & 0.00 & 1.26 & 0.57 \\
\hline C 20:2 (n-6) & 0.11 & 0.00 & 0.49 & 0.09 \\
\hline C 20:4 (n-6) & 0.00 & 0.00 & 0.01 & 0.00 \\
\hline C 22 & 0.12 & 0.13 & 0.07 & 0.18 \\
\hline C 22:1 & 0.08 & 0.04 & 0.07 & 0.07 \\
\hline C $22: 5(n-3)$ & 0.10 & 0.09 & 0.14 & 0.11 \\
\hline C 22:6 (DHA) $(n-3)$ & 0.00 & 0.01 & 0.01 & 0.01 \\
\hline SFA & 9.14 & 5.95 & 11.32 & 13.06 \\
\hline UFA & 90.86 & 94.05 & 88.68 & 86.94 \\
\hline PUFA $n-6$ & 45.60 & 49.05 & 57.68 & 55.97 \\
\hline PUFA $n-3$ & 29.16 & 33.12 & 17.30 & 0.96 \\
\hline PUFA $n-6 / n-3$ & 15.63 & 1.48 & 3.33 & 58.30 \\
\hline
\end{tabular}

3.2. Tocopherols and Tocotrienols in Oils from Blackcurrant, Raspberry, Strawberry, and Apple Seeds. In the analysed oils, the highest concentrations of tocols were identified in raspberry and blackcurrant seed oils (301.9 and $229.5 \mathrm{mg} / 100 \mathrm{~g}$ ) and lower levels in apple and strawberry seed oils (143.6 and $58.4 \mathrm{mg} / 100 \mathrm{~g}$, resp.). The dominant isomers of tocopherols in oils from raspberry, blackcurrant, and strawberry seeds were $\gamma$-and $\alpha$-tocopherol, and the same oils were poor in $\beta$ isomer (Table 3). A different pattern was evident for the profile of tocopherols in apple seed oil, in which the concentration of $\beta$ isomer was highest ( $62.7 \mathrm{mg} / 100 \mathrm{~g}$ ) compared to $\alpha, \delta$, and $\gamma$ isomers of $41.7,21.2$, and $13.6 \mathrm{mg} / 100 \mathrm{~g}$, respectively. In comparison with the results of Helbig et al. [3], the oil extracted from blackcurrant seeds had higher concentration of tocols and a similar profile. Goffman and Galletti [30] reported blackcurrant seed oil to contain a total of $1716 \mathrm{mg} / \mathrm{kg}$ tocopherols, of which $34.8 \%$ was $\alpha$-tocopherol, $60.2 \%$ was $\gamma$ tocopherol, and $5.0 \%$ was $\delta$-tocopherol. Meanwhile, Velasco and Goffman [31] found that blackcurrant seed oil contained a total of $531 \mathrm{mg} / 100 \mathrm{~g}$ tocopherols on average, of which $89.6 \%$ was $\gamma$ isomer. Shahidi and Shukla [9] reported that blackcurrant seed oil contained a total of $1500 \mathrm{mg} / \mathrm{kg}$ tocopherols on average.

The tocopherol content of oils from blackcurrant and raspberry seeds was comparable to commercial oils rich in tocopherol, that is, maize and soybean oils at 162 and $180 \mathrm{mg} / 100 \mathrm{~g}$ oil, respectively [32]. We can attribute differences in tocol levels to oil extraction method. The tocopherol content of oils is considerably affected by the refining process, which removes about $40 \%$ of tocopherol. In a study on oxidative stability of oils, Kamal-Eldin [33] found that problems in stabilizing vegetable oils by the addition of tocopherols are due to the fact that native tocopherols in these oils are at optimal levels necessary for their stabilization.

3.3. Phytosterols in Oils from Blackcurrant, Raspberry, Strawberry, and Apple Seeds. In most vegetable oils, sterols are the principal component of unsaponifiable substances, whose 
TABLE 3: Tocochromanol (tocopherol and tocotrienol) content of oils from strawberry, raspberry, blackcurrant, and apple seeds.

\begin{tabular}{|c|c|c|c|c|}
\hline Tocochromanols & Strawberry seed oil & Raspberry seed oil & Blackcurrant seed oil & Apple seed oil \\
\hline \multicolumn{5}{|l|}{ Tocopherols $(\mathrm{mg} / 100 \mathrm{~g})$ : } \\
\hline$\alpha$-Tocopherol & $2.46 \pm 0.8$ & $65.61 \pm 14.5$ & $84.32 \pm 7.5$ & $41.75 \pm 1.5$ \\
\hline$\beta$-Tocopherol & nd & $3.83 \pm 5.4$ & $4.44 \pm 2.4$ & $62.77 \pm 1.3$ \\
\hline$\gamma$-Tocopherol & $49.02 \pm 0.6$ & $193.58 \pm 29.9$ & $117.88 \pm 13.8$ & $13.60 \pm 2.4$ \\
\hline$\delta$-Tocopherol & $6.15 \pm 0.7$ & $32.17 \pm 13.3$ & $18.41 \pm 4.6$ & $21.28 \pm 3.3$ \\
\hline \multicolumn{5}{|l|}{ Tocotrienols (mg/100 g): } \\
\hline$\alpha$-Tocotrienol & nd & $1.84 \pm 2.5$ & $1.67 \pm 0.9$ & $1.21 \pm 0.6$ \\
\hline$\beta$-Tocotrienol & nd & nd & nd & nd \\
\hline$\gamma$-Tocotrienol & $0.85 \pm 0.6$ & $4.18 \pm 2.2$ & $2.07 \pm 1.2$ & $3.05 \pm 1.7$ \\
\hline$\delta$-Tocotrienol & nd & $0.71 \pm 0.7$ & $0.78 \pm 0.6$ & nd \\
\hline Sum of tocols $(\mathrm{mg} / 100 \mathrm{~g})$ & $58.48 \pm 5.7$ & $301.92 \pm 2.3$ & $229.57 \pm 23.1$ & $143.66 \pm 3.5$ \\
\hline
\end{tabular}

nd (not detected), limit of quantitative for each tocol is $0.5 \mathrm{mg} / 100 \mathrm{~g}$.

Values are mean \pm and coefficients of variation $(\mathrm{CV})$.

TABLE 4: Phytosterol content of oils from apple, blackcurrant, strawberry, and raspberry seeds ( $\mu \mathrm{g} / \mathrm{g})$.

\begin{tabular}{lcccc}
\hline Phytosterols & Apple seed oil & Blackcurrant seed oil & Strawberry seed oil & Raspberry seed oil \\
\hline Campesterol & $219.8 \pm 16.4$ & $513.4 \pm 5.7$ & $328.9 \pm 12.4$ & $254.7 \pm 20.2$ \\
Stigmasterol & $13.2 \pm 13.1$ & $44.6 \pm 3.0$ & $97.9 \pm 2.5$ & $60.7 \pm 3.7$ \\
Sitosterol & $2629.3 \pm 168.5$ & $3637.3 \pm 225.7$ & $2656.6 \pm 95.14$ & $3341.9 \pm 32.7$ \\
Sitostanol & $249.9 \pm 56.8$ & $300.9 \pm 36.3$ & $291.9 \pm 10.7$ & $364.6 \pm 18.4$ \\
Avenasterol & $347.8 \pm 6.3$ & $124.2 \pm 3.4$ & $47.5 \pm 3.2$ & $80.3 \pm 2.4$ \\
D7-Stigmasterol & 0 & $76.2 \pm 9.2$ & $108.2 \pm 3.7$ & $94.7 \pm 5.6$ \\
Cycloartenol & 0 & $775.6 \pm 26.9$ & $642.7 \pm 25.3$ & $449.8 \pm 21.2$ \\
D7-Avenasterol & 0 & $146.4 \pm 6.1$ & $158.7 \pm 9.2$ & $66.6 \pm 5.2$ \\
24-Methylene-cycloartenol & 0 & $931.9 \pm 47.7$ & $99.9 \pm 12.6$ & $523.8 \pm 17.1$ \\
Citrostadienol & 0 & $274.5 \pm 10.5$ & $210.7 \pm 13.4$ & $147.0 \pm 3.2$ \\
\hline Sum of phytosterols & 3460.0 & 6824.9 & 4643.1 & 5384.1 \\
\hline
\end{tabular}

Values are mean \pm and coefficients of variation $(\mathrm{CV})$.

content in blackcurrant and borage oil is $1.2 \%$ [9]. The main sterols of vegetable oils reported by Warner and Mounts [34] and Rudzińska et al. [35] are $\beta$-sitosterol, campesterol, stigmasterol, brassicasterol, $\Delta 5$-avenasterol, $\Delta 7$-stigmasterol, and $\Delta 7$-avenasterol (Table 4 ). In most oils, their total content ranges from 400 to $800 \mathrm{mg} / 100 \mathrm{~g}$, but there can be considerable differences in the content of these compounds between some oils $[9,36]$.

Chromatographic analysis of the oils revealed 10 different phytosterols. Oils from blackcurrant, raspberry, strawberry, and apple seeds contain considerable amounts of phytosterols. The richest sources of phytosterols were blackcurrant seed oil $(6824.9 \mu \mathrm{g} / \mathrm{g})$ followed by raspberry $(5384.1 \mu \mathrm{g} / \mathrm{g})$, strawberry $(4643.1 \mu \mathrm{g} / \mathrm{g})$, and apple seed oil $(3460.0 \mu \mathrm{g} / \mathrm{g})$.

The dominant compound in the analysed oils was sitosterol, whose content ranged from $2630 \mu \mathrm{g} / \mathrm{g}$ in apple seed oil to $3630 \mu \mathrm{g} / \mathrm{g}$ in blackcurrant seed oil. Sitosterol is an important phytosterol that reduces the absorption of cholesterol, which helps to maintain a low level of total cholesterol in peripheral blood. The analysed samples also contained considerable amounts of other phytosterols such as campesterol, sitostanol, cycloartenol, and citrostadienol. Unlike cholesterol, phytosterols generally have a positive effect on human health. They bind bile acids and reduce the risk of high blood levels of total cholesterol without affecting the levels of HDL cholesterol [37]. Another positive effect of phytosterols is that they inhibit the development of intestinal cancer. In human and animal bodies, phytosterol shows mainly anticarcinogenic, antioxidative, and cholesterol-lowering activities [38].

\section{Conclusions}

The oils obtained from strawberry, blackcurrant, raspberry, and apple seeds are a rich source of essential unsaturated fatty acids (EUFA), tocochromanols and phytosterols, which could find wide application in the cosmetic, pharmaceutical, and food industries.

The native oils from strawberry, raspberry, blackcurrant, and apple seeds can be regarded as special oils (biooils), which, due to their possible nutraceutical effects, could find broader use not only in the cosmetic but also in the food industry. They could find special application in the design and production of foods with specific health-promoting effects, rich in various bioactive components helpful in preventing metabolic diseases of modern civilization. 


\section{Conflict of Interests}

The authors declare that there is no conflict of interests regarding the publication of this paper.

\section{References}

[1] B. Nosecka, "Fruit and vegetable processing. Information for processors," in Polish Village in Europe. Fruit \& Vegetables Industry, Cooperation Fund, Office of Rural Programs, Warsaw, Poland, 2005 (Polish).

[2] K. Kołodziejczyk, J. Markowski, M. Kosmala, B. Król, and W. Płocharski, "Apple pomace as potential source of nutraceutical products," Polish Journal of Food and Nutrition Sciences, vol. 57, no. 4, pp. 291-295, 2007.

[3] D. Helbig, V. Böhm, A. Wagner, R. Schubert, and G. Jahreis, "Berry seed press residues and their valuable ingredients with special regard to black currant seed press residues," Food Chemistry, vol. 111, no. 4, pp. 1043-1049, 2008.

[4] J. Markowski, K. Kołodziejczyk, B. Król, W. Płocharski, and K. Rutkowski, "Phenolics in apple processed apple products," Polish Journal of Food And Nutrition Sciences, vol. 57, no. 4, pp. 383-388, 2007.

[5] B. D. Oomah, S. Ladet, D. V. Godfrey, J. Liang, and B. Girard, "Characteristics of raspberry (Rubus idaeus L.) seed oil," Food Chemistry, vol. 69, no. 2, pp. 187-193, 2000.

[6] J. Parry and L. Yu, "Fatty acid content and antioxidant properties of cold-pressed black raspberry seed oil and meal," Journal of Food Science, vol. 69, no. 3, pp. 189-193, 2004.

[7] R. L. Tahvonen, U. S. Schwab, K. M. Linderborg, H. M. Mykkänen, and H. P. Kallio, "Black currant seed oil and fish oil supplements differ in their effects on fatty acid profiles of plasma lipids, and concentrations of serum total and lipoprotein lipids, plasma glucose and insulin," The Journal of Nutritional Biochemistry, vol. 16, no. 6, pp. 353-359, 2005.

[8] Š. Schmidt and J. Pokorný, "Potential application of oilseeds as sources of antioxidants for food lipids-a review," Czech Journal of Food Sciences, vol. 23, no. 3, pp. 93-102, 2005.

[9] F. Shahidi and V. K. S. Shukla, "Nontriacylglycerol constituents of fats, oils," Inform, vol. 7, no. 11, pp. 1227-1232, 1996.

[10] K. B. Filion, F. El Khoury, M. Bielinski, I. Schiller, N. Dendukuri, and J. M. Brophy, "Omega-3 fatty acids in high-risk cardiovascular patients: a meta-analysis of randomized controlled trials," BMC Cardiovascular Disorders, vol. 10, article 24, 2010.

[11] R. Kapoor and Y.-S. Huang, "Gamma linolenic acid: an antiinflammatory omega-6 fatty acid," Current Pharmaceutical Biotechnology, vol. 7, no. 6, pp. 531-534, 2006.

[12] M. Pieszka, B. Tombarkiewicz, A. Roman, W. Migdał, and J. Niedziółka, "Effect of bioactive substances found in rapeseed, raspberry and strawberry seed oils on blood lipid profile and selected parameters of oxidative status in rats," Environmental Toxicology and Pharmacology, vol. 36, no. 3, pp. 1055-1062, 2013.

[13] N. P. Seeram, L. S. Adams, Y. Zhang et al., "Blackberry, black raspberry, blueberry, cranberry, red raspberry, and strawberry extracts inhibit growth and stimulate apoptosis of human cancer cells in vitro," Journal of Agricultural and Food Chemistry, vol. 54, no. 25, pp. 9329-9339, 2006.

[14] R. Zadernowski, B. Lossow, B. Nowak-Polakowska, and J. Nesterowicz, "Fruit of berry plants as a source of bio-oils," Polish Journal of Food and Nutrition Sciences, vol. 4/45, no. 4, pp. 5562, 1995.
[15] J. J. Loor and J. H. Herbein, "Alterations in blood plasma and milk fatty acid profiles of lactating Holstein cows in response to ruminal infusion of a conjugated linoleic acid mixture," Animal Research, vol. 50, no. 6, pp. 463-475, 2001.

[16] W. R. Morrison and L. M. Smith, "Preparation of fatty acid methyl esters and dimethylacetals from lipids with boron fluoride-methanol," Journal of Lipid Research, vol. 5, pp. 600$608,1964$.

[17] R. Gąsior, M. Pieszka, and F. Brzóska, "Validation of a method for simultaneous determination of tocopherols and tocotrienols in cereals using normal Phase HPLC," Journal of Animal and Feed Sciences, vol. 18, no. 1, pp. 173-192, 2009.

[18] G. Panfili, A. Fratianni, and M. Irano, "Normal phase highperformance liquid chromatography method for the determination of tocopherols and tocotrienols in cereals," Journal of Agricultural and Food Chemistry, vol. 51, no. 14, pp. 3940-3944, 2003.

[19] R. R. Eitenmiller and W. O. Landen, Eds., Vitamins Analysis for the Health and Food Sciences, CRC Press, Boca Raton, Fla, USA, 1999.

[20] "AOCS Official Method Ch 6-91 Determination of the composition of the sterol fraction of animal and vegetable oils and fats by TLC and capillary GLC," in Official Methods and Recommended Practices of the AOCS, D. Firestone, Ed., American Oil Chemists' Society, Urbana, Ill, USA, 6th edition, 1997.

[21] "Vegetable and animal fats and oils. Determination of acid value and acidity," PN-EN ISO 660, 2005 (Polish).

[22] "Vegetable fats and oils and animal. Determination of peroxide," PN-EN ISO 3960, 2005 (Polish).

[23] Y. Lu and L. Y. Foo, "Constitution of some chemical components of apple seed," Food Chemistry, vol. 61, no. 1-2, pp. 29-33, 1998.

[24] R. Yukui, W. Wenya, F. Rashid, and L. Qing, "Fatty acids composition of apple and pear seed oils," International Journal of Food Properties, vol. 12, no. 4, pp. 774-779, 2009.

[25] M. Hilder, "Oxidation of oils," in Lipid Ttechnologies and Applications, F. Gunstone and F. Padley, Eds., pp. 178-188, Marcel Dekker, New York, NY, USA, 1997.

[26] W.-S. Choo, J. Birch, and J.-P. Dufour, "Physicochemical and quality characteristics of cold-pressed flaxseed oils," Journal of Food Composition and Analysis, vol. 20, no. 3-4, pp. 202-211, 2007.

[27] F. Anwar, S. Latif, and M. Ashraf, "Analytical characterization of hemp (Cannabis sativa) seed oil from different agro-ecological zones of Pakistan," Journal of the American Oil Chemists' Society, vol. 83, no. 4, pp. 323-329, 2006.

[28] J. T. Budin, W. M. Breene, and D. H. Putnam, "Some compositional properties of camelina (Camelina sativa L. Crantz) seeds and oils," The Journal of the American Oil Chemists' Society, vol. 72, no. 3, pp. 309-315, 1995.

[29] J. L. Guil-Guerrero, F. F. García-Maroto, and A. GiménezGiménez, "Fatty acid profiles from forty-nine plant species that are potential new sources of $\gamma$-linolenic acid," Journal of the American Oil Chemists' Society, vol. 78, no. 7, pp. 677-684, 2001.

[30] F. D. Goffman and S. Galletti, "Gamma-linolenic acid and tocopherol contents in the seed oil of 47 accessions from several ribes species," Journal of Agricultural and Food Chemistry, vol. 49, no. 1, pp. 349-354, 2001.

[31] L. Velasco and F. D. Goffman, "Chemotaxonomic significance of fatty acids and tocopherols in Boraginaceae," Phytochemistry, vol. 52, no. 3, pp. 423-426, 1999. 
[32] C. I. G. Tuberoso, A. Kowalczyk, E. Sarritzu, and P. Cabras, "Determination of antioxidant compounds and antioxidant activity in commercial oilseeds for food use," Food Chemistry, vol. 103, no. 4, pp. 1494-1501, 2007.

[33] A. Kamal-Eldin, "Effect of fatty acids and tocopherols on the oxidative stability of vegetable oils," European Journal of Lipid Science and Technology, vol. 108, no. 12, pp. 1051-1061, 2006.

[34] K. Warner and T. L. Mounts, "Analysis of tocopherols and phytosterols in vegetable oils by HPLC with evaporative lightscattering detection," Journal of the American Oil Chemists' Society, vol. 67, no. 11, pp. 827-831, 1990.

[35] M. Rudzińska, T. Kazuś, and E. Wąsowicz, "Sterols and their oxidized derivatives in refined oils and cold pressed," Oilseeds Crops, vol. 22, pp. 477-494, 2001 (Polish).

[36] W. W. Nawar, "Chemistry," in Bailey's Industrial Oil \& Fat Products, Y. H. Hui, Ed., pp. 397-426, John Wiley \& Sons, New York, NY, USA, 1996.

[37] S. M. Mel'nikov, J. W. M. Seijen ten Hoorn, and A. P. A. M. Eijkelenboom, "Effect of phytosterols and phytostanols on the solubilization of cholesterol by dietary mixed micelles: an in vitro study," Chemistry and Physics of Lipids, vol. 127, no. 2, pp. 121-141, 2004.

[38] D. Kritchevsky and S. C. Chen, "Phytosterols-health benefits and potential concerns: a review," Nutrition Research, vol. 25, no. 5, pp. 413-428, 2005. 

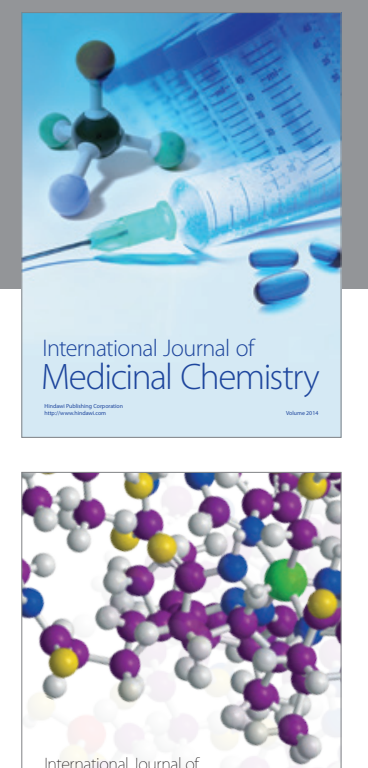

\section{Carbohydrate} Chemistry

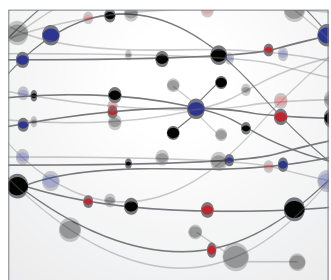

The Scientific World Journal
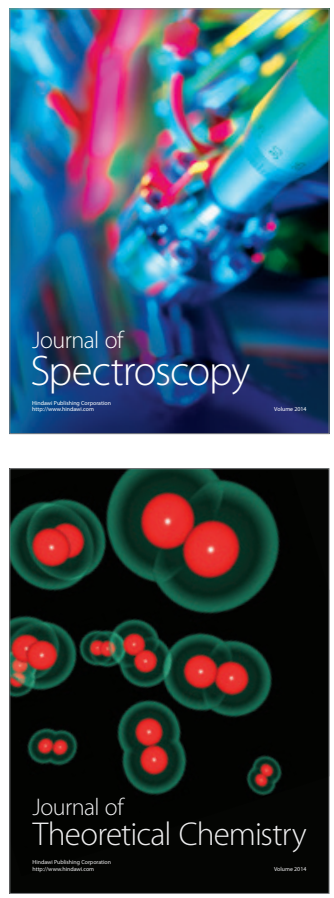
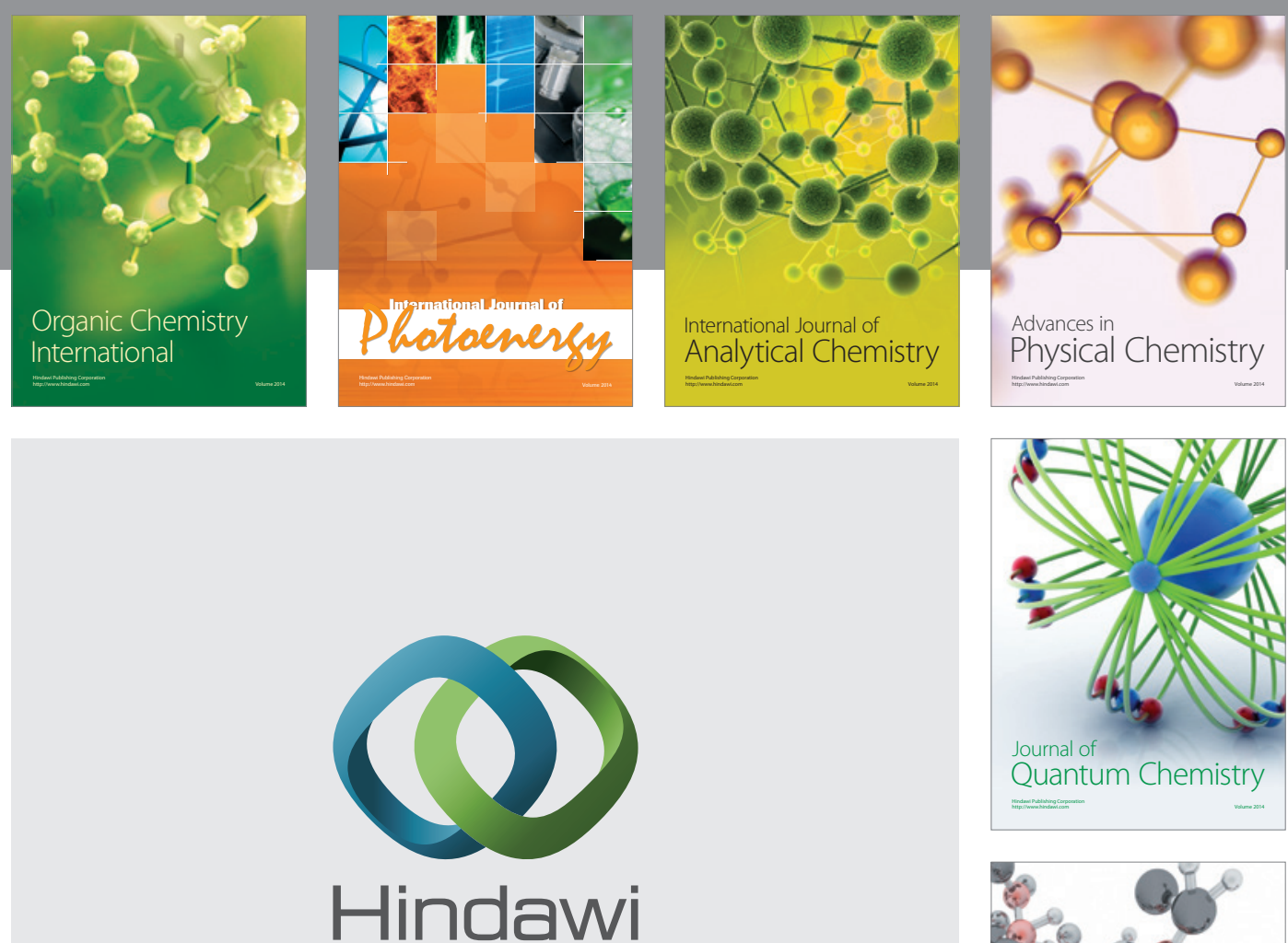

Submit your manuscripts at

http://www.hindawi.com

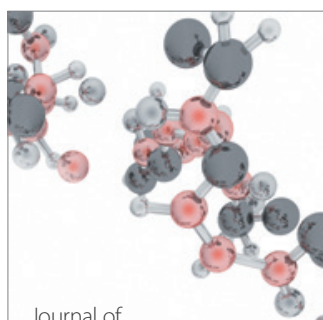

Analytical Methods

in Chemistry

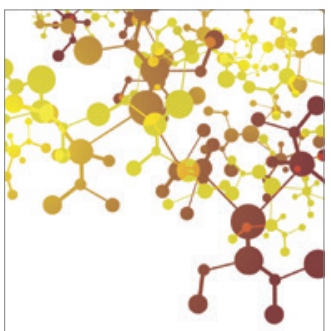

Journal of

Applied Chemistry

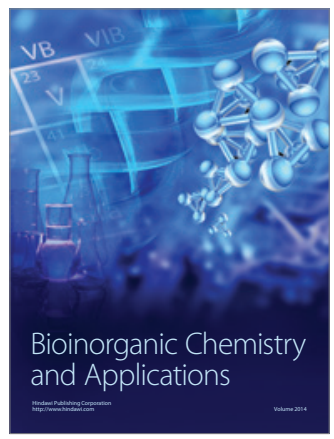

Inorganic Chemistry
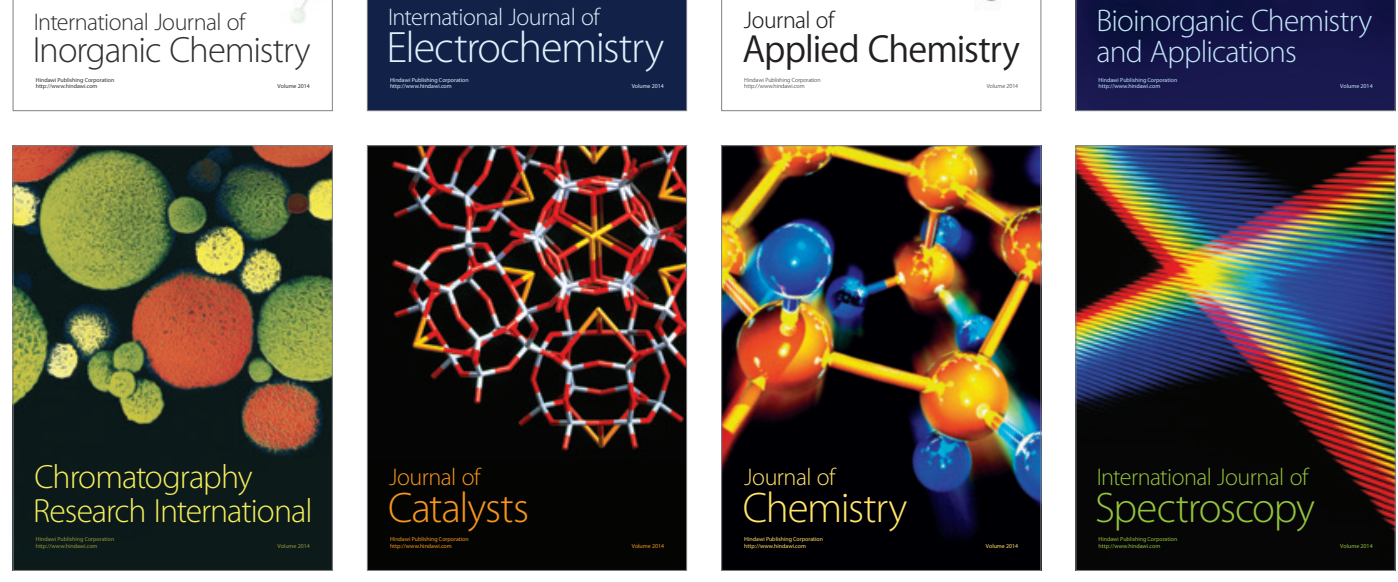